https://doi.org/10.48009/1_iis_2006_199-203

\title{
ASSESSING ACADEMIC INTEGRITY OF THE IS/IT EDUCATION: 12 CRITICAL QUESTIONS TO ASK FOR PROGRAM REVIEW
}

\author{
L. Roger Yin, Univ. of Wisconsin-Whitewater, USA, yinl@uww.edu \\ Robert Brookshire, Univ. of South Carolina, USA, brookshire@ sc.edu
}

\begin{abstract}
This paper proposes a proactive over reactive approach to examine a self-conscious and self-critical assessment of the academic integrity of the IS/IT program. It is suggested that we take a holistic view at our curriculum as we are refocusing on the proper "big picture" instead of the more conventional piecemeal "jigsaw puzzle" approach where each course is taken as a piece of the puzzle. To meet the requirement of the program review, a program selfstudy is an indispensable component. By asking ourselves a set of important and relevant questions, we may find the answers clearer and simpler than expected.
\end{abstract}

Keywords: Assessment, Curriculum Design, Assurance of Learning, Information Systems Education, Information Technology Education, Accreditation, AACSB

\section{INTRODUCTION}

In the midst of an unsettling economy of the globalization movement, corporations and governments have second thoughts regarding their IS/IT investment in both technological solutions and personnel cost [3]. Many technical jobs have become commodity and get outsourced or shifted overseas from North America [2]. Over a decade ago, Trauth and Farwell [4] identified a gap between IS/IT industry expectations and academic preparation. Continuous curriculum redesign and course updates are necessary to provide students with the essential skills needed upon graduation. Therefore, educational institutions must be willing to review their own curricula and investigate how to update their curricula to produce technically competent students with the skills necessary to succeed in the business world. The trickle-down effect has impacted the academic IS/IT disciplines, in the entire life-cycle of a student's college career: enrolment, retention, and placement. While the number of students committed to the IS/IT related programs decreases rather sharply, many of our graduates are experiencing uncertainty in securing technology-related jobs. Internally, the IS/IT programs are facing rigorous evaluation based on the outcome-driven assurance of learning initiatives made by agencies like AACSB [1]. Accountability and accreditation outcomes determine the fate of a large number of the IS/IT programs at the crossroads.

To fulfill the accreditation review requirement, we need to conduct self-study of our program. By asking ourselves a set of important and relevant questions as a "road map" based on who we are, where we are, and where do we want to go from here, we may find the answers clearer than expected. As a point of reference, readers who may conduct program reviews and selfstudies could consider incorporating a number or the entire set of questions listed below to guide the review process.

\section{TWELVE CRITICAL QUESTIONS TO ASK OURSELVES}

1. Does the program have clearly stated goals and objectives?

Clearly defined and articulated goals and objectives can be related to learning outcomes and employment demand that ensures the program remains both current and marketable. Some element lacking student demand for the program may be as a result of a less than clear understanding of the connection between the program and graduate studies and career opportunities. Strategically planning, developing, seeking approval for, and publishing these goals and objectives would be a worthwhile exercise for the department. An external industry-based Advisory Board may be formed to help facilitate the formation of these goals and objectives. Only when the program has clear goals and objectives, the evaluation and assessment methods could take place to ensure the evidence and assurance of learning are actually present upon student graduation from the program.

2. Does the curriculum reflect these goals and objectives?

If the goals and objectives of the program are not clear, there can be no test of their presence in the curriculum. Nevertheless, it is clear that the 
restructured IS/IT curriculum must possess a purpose to balance "hard skills" (computer networking, scripting/coding, and related technical capacities) with "soft skills" (communications, negotiation, problem-solving and related abilities). A professional curriculum is like a knowledge management system. Finding the proper proportion among levels of literacy, competency, and fluency of both hard and soft skills and knowledge throughout the curriculum must match the guiding goals and objectives of the program.

3. Does the curriculum represent the disciplinelfield adequately? If not, what elements are missing?

The redesigned IS/IT curriculum should reflect the applied and practical nature of the field that is grounded in theories as well as tried-and-true best practices. It is important to recognize student choices and enable students to pursue subjects of interest to them within reason. However, many existing IS/IT curricula may have an inappropriate level of sophistication and exceedingly broad content breath in some critical areas and may be over-emphasizing lower-level piecemeal skills which may be lacking the depth in real-world applications.

Prescribing courses on vendor-specific programming languages, database programs, operating systems, and Internet work solutions often yields the result that the students know many tools but lack the understanding of the context and purpose. To put the IS/IT curriculum back to the perspective based on business needs and requirements, a specific course (or more) should be offered in the following areas, depending on the core competency and strength identified by the program stakeholders:

- Project Management (introduction to the standard single project methodology)

- Enterprise IT Service Management (multiple projects, enterprise-wide, ITIL)

- Human Computer Interaction (HCI)/Interface Design (usability testing)

- Information System Analysis (both theory of and hands-on database design)

- Knowledge Management Systems (as distinct from database or records mgmt.)

- ERP/Supply Chain Management (an essential element of enterprise technology)

- Consulting \& Training (consulting/training methodologies, persuasion negotiation)

- Business \& Technical Communications (essential to success in human society)
- Enterprise Network Infrastructure and Security (design \& deployment of Wide Area Network)

In order to accomplish this level of curricular robustness and integrity of a "big picture," development will require an acknowledgement by the college and the university the need to support with adequate resources to ensure course relevance with continuous updates and improvement.

4. Is the structure of the curriculum well articulated? Is there logic to the order of the courses and to the prerequisites required? Is there increasing complexity in the learning expectations as the student progress through the curriculum? Are the learning objectives appropriate to the level of course?

One common problem which occurs in the field of IS/IT education is the constant assignment of busy work and assumption the students will find out by themselves why they need to work so hard. Learning is a sense-making process. It is imperative to help the students envision the "big picture" in the introductory courses on why we are doing it, instead of the non-stop which is what and how to do it. The why empowers the students to find the meaning and reason for their college experience in our field (otherwise, they should choose a different major), and the which one and how elements could be picked up - to a certain extent - much more easily by the students when they form and take over their own learning expectation by experiencing the increased complexity in course rotation. The self-purpose and self-motivation should be the key logic behind course sequencing and decisions on prerequisites: does it make sense to everyone involved including the students? Accordingly, the courselevel objectives need to be reassigned to nurture higher level competency and fluency in practical and inventive knowledge while assuring their acquisition of lower level competency and literacy in general and specific knowledge.

5. Are the modes of delivery of the curriculum appropriate? Are innovative approaches being used in delivering the program, including $e$ learning (Blackboard, WebCT, etc.)? Are experiential learning opportunities (co-op, internship, etc.) appropriate?

Learning could take place anytime, anywhere. Therefore the infrastructure of instructional support and "points of contact" should be 
adequately provided. As a professional group in the IS/IT field, the faculty must demonstrate both an awareness of and desire to embrace the role of technology in and outside the classroom. We need to remember that the incoming "gamer generation" students play to win and get bored easily. In addition, co-op and internship are the best possibly ways for students to gain real-world work experience as aspiring professionals. Knowing a well-organized co-op and internship could impact the students' future career development opportunities and understanding of the value of what they have learned in the classroom, it is suggested that a co-op or internship be required instead of recommended or optional before their graduation.

6. Are the methods and standards of evaluation of student learning appropriate?

Since we are in an applied and practical field, the evidence-based assessment and evaluation is a logical choice. In addition to the GPA scores that provide the measurable and quantifiable elements of student achievement, additional sources of evidence, such as a digital portfolio that documents the progress they make through videotaping their topical mini-research presentations, compiling technical training document write-ups (i.e., the best way to learn is via preparing to teach), constructing and improving their personal Web portals (i.e., online resumes), etc. In reality, employers care more about what the graduates can perform and contribute immediately based on the changing needs of the company, instead of merely GPA and a collection of courses taken.

7. Does the Department work well together to develop and improve program?

The collegiality and mutual respect inside the department is important to the continuous success of a program. The openness and willingness to listen to comments and feedback and to consider them thoughtfully and appropriately should always be encouraged, if not rewarded. Inevitably, there may be frustration within the department about what the faculty see as the lack of success which is accruing to a program that they deeply believe in. It is totally understandable that this frustration exists and perhaps external opinions (from Advisory Board, peer institutions, etc.) could be one of the possible methods that is used to help the faculty channel their abundant energy and commitment into a renewed sense of purpose followed by a demonstrable improvement in results.

8. What strengths and weaknesses of the program are identified by students and alumni? What role have students and alumni had in developing and revising curriculum in the program?

Students and alumni are important stakeholders in the curricular redesign, simply because they are at the recipient side of the educational process. For instance, if the students show signs to express concerns that appropriate resources were not made available to the faculty on which to teach more advanced courses, or that this technology was not always of the latest iteration or version to reflect industry needs, the department must react promptly before it is too late.

Better yet, the department could formulate a mechanism to formally incorporate comments and feedback from students and alumni regularly or even change the inappropriate parts of a course on the fly. In the new millennium that the only thing does not change is change itself, the department must keep the program current, relevant and responsive by involving all stakeholder as participants in the curricular redesign processes.

9. How effective is the program in preparing students to think creatively and critically, communicate effectively, and act ethically?

There is one fundamental consideration: how open are we in the department and the program to allow and encourage students to freely ask questions regarding their learning experience? Perhaps we ought to understand the fact that there are no stupid questions but stupid mistakes. Teaching and learning must be a two-way street, since we the faculty, like the students, are exposed to new situations and challenges hence learning everyday as well. To nurture critical thinking, we must encourage the students to raise questions that were not asked before, and help them find the answers. In fact, learning to ask the right question is essential in conducting research at all levels. To ensure that they become effective communicators, we must let them report their creative findings in the forms of topical presentations and training documents. A common finding is that the students who are entitled to their own intelligence and pride could be more critical about their own performances than we as judges. Also, we the faculty are role models to the students, particularly those who do not have real-world work 
experience, so we must act ethically ourselves and "walk the talk" for students to follow suit. The emphasis of the university education, rather than on transferring technical skills, must be on not only learning to learn, but also learning to question. We must begin treating our students as intellectuals and democratic citizens - that is what mentoring is all about.

10. What are the enrolment levels in the program and are they adequate to sustain a quality program? Are there suggestions for immediate or longer term changes in the program to enhance student interest?

In the midst of IS/IT outsourcing and offshoring, it is commonplace that the enrolment levels in our programs are showing signs of decline. Knowing the academia always catches on a few years behind the corporate environment, the problem also presents itself as an opportunity. What have we, in the program, done so well that we should keep doing it? What parts have we failed to deliver or adhere to the program goals and objectives that we must change or get rid of? These tough decisions often tie directly to the personnel and resource issues both internally and externally to the program. Growing an academic program is like growing a family - it takes a lot of patience, devotion, and reasonable expectation. Current enrolment levels probably do not justify enhancing the resource base of the program; however, without an increase in resources, program quality may continue to suffer. This conundrum should be made clear to all stakeholders. As a result, the faculty need to form a reasonable and doable plan on how to address this issue and move forward positively and productively but with an eye to the practical realities of the constraints faced by the university and its senior decision-makers in the current context.

11. What is the level of scholarly activity in the Department? Is it equivalent to that at other primarily undergraduate universities? Does the scholarship support the academic goals and objectives of the program?

It is mission-critical to have the faculty keep an active scholarly agenda to sustain the expertise in the field. Most institutions require faculty to publish and present refereed research papers to be qualified to teach graduate-level courses. Since we are moving towards an applied and practical direction, the members in the department and program should determine the most reasonable number of publications and professional presentations, and a reasonable balance between empirical and pedagogical research for tenure, promotion, and post-tenure review purposes. The ongoing scholarly development will secure not only academic prestige but also promised support for the program goals and objectives.

12. Are the resources to support the program adequate and effective?

Faculty - the size of our current program usually results in two staffing issues: either over-staffed or under-staffed. The latter in particular makes course coverage and subject diversity very difficult. To exacerbate the situation, there has been a concern that the general trend within the university is to use part-time or itinerant faculty to teach significant numbers of degree courses and that the committee feels that, while this is certainly economically efficient and should not be abandoned, the corollary negative impact on having an overburdened full-time faculty and uncommitted teachers has not been sufficiently considered in making staffing and appointment decisions.

Support Staff - depending on the size of the program, support staff resources should be in line with other similar departments and programs. As the program/department grows, it needs to be ensured that staff resources also grow but more selectively and in second priority to increasing faculty resources.

Space - this will become a substantial issue if the lab capacity (i.e., computers per seat, server/user ratio, hands-on labs, etc.) appears to be inadequate. Usually the spatial limitation sets a natural cap for how many students we can allow to enroll into our program. It will be a disservice to both program faculty and particularly the students if inadequate space is allocated per student in a learning environment.

Technical - the relationship with university and college level information technology and computing services is vital for the program to be properly supported. A sound computing technology infrastructure on campus will also ensure the consistency and adequacy for both classroom-based and online teaching and learning. Our program could maintain a constructive and positive relationship by (1) having our faculty members sit in a variety of campus information technology committees, (2) inviting computing center staff as quest speakers or to team-teach with 
our faculty members whenever is necessary and could be arranged. If it is planned and executed properly, the results will be mutually beneficial for the program and the computer center, plus the students will be the greatest beneficiaries.

\section{CONCLUSION: \\ THE BOTTOM LINE - LIVE OR LET DIE?}

The newness and constant changing face of a discipline cannot be equated to its importance; IS/IT is now firmly in place as a discipline of the future and is taking its rightful place in the hierarchy of academic rigour and pursuit of knowledge elsewhere rapidly. The issue of currency and competency in selected parts of this field among existing faculty could be addressed by continuous faculty teaching and scholarship development and recruiting the "best fits" of the new hires in the program. Also, the commitment and engagement of the faculty in professional activities helps keep the "brand" of the program connected to industry.

Today's IS/IT programs are the epitome of applied education - relevant and profession-driven, but still with a few to graduating those that think and reflect about the problems of the real world. A deemphasizing of specific, current technical skills and a strengthening of underlying theory and the "big picture" in key areas would enhance program quality and perhaps help address some of this perceptual deficit. However, in the midst of the globalization, the IS/IT discipline is at a crossroads and must determine a new mindset and how it will provide the collective energy necessary to complete the transformation of the program from its origins to its true future potential.

\section{REFERENCES}

1. AACSB International (2006). Accreditation standards: Assurance of learning standards. Retrieved May 31, 2006, from http://www.aacsb.edu/resource_centers/assessme nt/standards.asp

2. Baker, S., Kripalani, M., Hof, R., \& Kerstetter, J. (2004, March 1). Software: Programming jobs are heading overseas by thousands. Is there a way for the U.S. to stay on top? Retrieved May 31, 2006, from http://www.businessweek.com/magazine/content/ 04_09/b3872001_mz001.htm

3. Giddens, A. (2002). Runaway world: How globalization is reshaping our lives. London: Routledge.

4. Trauth, E. M., Farwell, D. W. \& Lee, D. M. S. (1993). The IS expectation gap: Industry expectations versus academic preparation, MIS Quarterly, 17(3), 293-307. 